\title{
INTEgRATION OF 360-DEgREe PHOTOGRAPHY AND VIRTUAL REALITY INTO MUSEUM STORAGE FACILITY DESIGN AND EDUCATION
}

\author{
Marzia Loddo \\ Department of Heritage \& Architecture, Faculty of Architecture and the Built \\ Environment, Delft University of Technology, \\ Julianalaan 134, 2628 BL, Delft, The Netherlands
}

\begin{abstract}
The use of digital tools in architecture and design education has been experimented with since the 1990s. The representation and communication of architectural narratives have been facing an unprecedented challenge in education, research, and practice during the past couple of years. This study investigates if using 360-degree photography/video and virtual reality (VR) technologies can be beneficial in architectural education. It focuses on museums and their storage facility areas and buildings, and looks at how digital technologies can raise awareness of these spaces and improve future museum designs. Starting from the fact that museums usually lack a proper storage area due to wrong designs, this project has investigated how the subject of museums is treated in design courses and, how VR representation could help students visualise and immersively navigate an area usually not known to many: the storage facility. The digital representation of real objects and the environment using 360-degree photography/video and $V R$ technologies were tested on international architecture students in The Netherlands and Germany. The research methods combined qualitative and quantitative approaches (e.g., interaction, surveys, interviews, and visual/narrative devices) related to museums and cyber-ethnography. The results demonstrate how the digital tools positively affected students' consciousness of museums and architectural qualities and how they inspired students to explore the area further. Students became more engaged and motivated throughout the workshops; they were able to learn from and compare different resources, providing valuable quanti-qualitative results. This paper will describe how 360-degree photography and VR visualisation were integrated into the existing teaching approaches.
\end{abstract}

\section{KEYWORDS}

Virtual Reality, Virtual Navigation, 360-degree photography, Design Education, Museums Design, Storage Facility.

\section{INTRODUCTION}

In the design process, architects have always been asked to be creative and think outside of the box. To do so, designers sketch, draw and create maquettes and mock-ups; therefore, they have always seemingly worked in a virtual world. Architecture as a virtual state existed long before the term 'virtual reality' was coined by Jaron Lanier in 1987 [1]. Nonetheless, the first experiments with a VR head-mounted display (HMD) were in 1965, but they were too heavy to wear [1]. The use of VR in design education has been tested since the 1990s [2], especially in using a VR interface to engage users in assessing designs during project review meetings [3]. With the spread of popular video games, the creation of Oculus VR in 2012, and the realisation of affordable Google cardboard headsets in 2014, the use of VR has quickly become mainstream [4]. Users now have the opportunity to easily move around virtual environments with low-cost hardware 
and to access emerging software links to digital modeling tools, which has made it possible to integrate VR into architecture and design studios [5; 6]. Students can use an immersive environment to visualise their projects, enrich their spatial understanding to achieve a better design [7]. In this contribution, the preliminary results of the digital representation of real objects and the environment using 360-degree photography/video and VR technologies on international architecture students at the Delft University of Technology (TUD hereafter) and the Technical University of Ostwestfalen-Lippe (Germany) (TH-OWL hereafter) are described. The project focused on museums and their storage facility areas and buildings, and looked at how digital technologies can raise awareness on these spaces and improve future museum designs, education and curatorial activities, and engaging projects.

Museums have always been interested in finding new ways of entertaining the audience and informing them about their activities. One way could be by digital technologies such as 360 degree photography, augmented, mixed and virtual reality (AR, MR \& VR), games, etc. VR and AR are very different. The first offers a total immersion in virtual reality, while the AR shows the reality and an altered digital version one next to the other. To use AR, one needs to use a device such as a smartphone or a tablet, and to download the apps. As for MR, it combines elements of both AR and VR, and allows users to manipulate and interact with elements of both the real and the digital world [8]. For example, one can take a virtual box from our real bedside table, open it, and see what is inside. MR is a kind of immersive AR, no longer tied to a limited screen or viewer. Instead, it uses special equipment: a headset or glasses with controllers, just like VR.

\section{The SubJect of Museums in Architecture AND Design EDUCATION}

Within this study, the author could investigate how the topic of museums design is dealt with in architecture and design courses. A common assignment in an architecture course is to formulate a transformation framework and starting points for designing a museum. Students are asked to present a final design that should demonstrate their knowledge and understanding of interactions between an architectural concept and a building engineering concept. They should develop and elaborate on sustainable technical aspects, such as construction, structure and climate. Thus, students should present reasoned solutions and demonstrate skills in incorporating a sustainable, technical building design effectively in the design process as a whole. Teachers and professors give their students a literature list, which often comes from their departments and could include subjects related to heritage and architecture. Sometimes, a person strongly related to the subject of design is asked to give a lecture on a specific topic to bring their view and points of discussion to the project.

Direct experience, observations and discussions with professors and teachers in Italy, Germany and the Netherlands indicate that it could be possible to distinguish between two main teaching and pedagogical approaches. In one, students strictly study from the literature suggested by their teachers and follow their instructions and assignments. In the other approach, students are guided by their teachers who give feedback and yet still allow students to explore, reflect, experience and seek their path. In this autodidactic yet guided approach, the final goal is not about solving the problem but how, as a designer, one can approach a certain problem by talking, thinking and openly discussing.

If an architect receives a commission for a particular kind of building, e.g., a museum, hospital, bank, or housing complex, it usually involves extra homework to become acquainted with specific demands, regulations and considerations. Time is usually not enough to examine all of the important aspects of museums, from architecture and engineering concepts to preventive 
conservation and the final use of the building. Later, in practice, they will have the opportunity to see specific cases in detail, operating within a team and collaborating with consultants [9]. This will guarantee that their assignment will be more effective and successful. However, regardless of the approach chosen, it is important to help students and provide them with the necessary tools so that they can be creative in their design work but also rely on facts that reflect the complexity of the museum.

Literature on museum design does not cover all of the aspects related to museums' functions (e.g., practical information on facility management, preventive preservation, storage facilities). Moreover, practitioners who are sometimes invited to courses to provide practical insights do not always cover all of these aspects. However, final course assignments are very specific, and students are often asked to provide a new museum setting that should include, among other things, permanent and temporary exhibitions, offices, archives, conservation studios, storage space and installation rooms. To enable students to complete these projects, it may be important to know how many objects are included in a permanent collection, how many will be exhibited and how many will be put into storage. It would also be helpful to know how many people usually work in a museum. Very often, this information is missing from course assignments, but how can a design be efficient if these requirements are not taken into consideration? As aforementioned, students in design studios learn how to approach problems. However, VR and digital tools can offer in-depth exploration of designed environments that is not possible with traditional forms of representation as they allow users to immerse themselves, visualise and explore spaces during different design stages and before they are built. Therefore, students should be able to use these technologies to learn about different aspects of a museum (and other building typologies). Too many museums, also newly designed ones, show unfitted storage areas, either because they do not meet the conditions of safety (from a variety of threats) and a suitable space to evaluate the artworks, and do not anticipate the growth of the collection over the years [10].

These practical issues led to investigate how the subject of museums is treated in design courses and, how VR representation could help students visualise and navigate an area usually not known to many: the storage facility. VR museums and exhibitions, which have increased enormously in the past few years, usually focus on the good representation of artworks more than the architecture [11]. Museums' storage facilities are rarely shown and represented. Thus, this study included the realisation of virtual museum storage areas that were incorporated as a tool in various classroom settings. The research methods combined qualitative and quantitative approaches related to museums (e.g., interaction, surveys, interviews and visual devices) and cyber architecture ethnography.

The results demonstrate how the digital tools affected students' consciousness of museums and architectural qualities and how they inspired students to explore the subject further. Students became more engaged and motivated throughout the workshops; they were able to learn from and compare different resources, providing valuable results.

\section{Methodology}

The study was conducted with bachelor and master's students, and Ph.D. candidates in architecture and design between September 2020 and January 2021. Forty-three students attended the TUD, and eighteen students attended the Detmold School of Architecture and Interior Architecture at the TH-OWL. The participants' age varies between twenty and thirty-three years old. The study was conducted during workshops organised within the design courses, which included lectures and experiments with 360-degree navigation and VR representations. Each workshop sessions lasted 02:45 hours each including 61 students composed mainly of the 4th year of the Architecture track (17 students), but also Ph.D. candidates (10) and, bachelor and 
master students from Landscape Architecture (1), Facade Design (9), Integrated Design (9), Industrial Design (2), Aerospace Engineering (1), Physics (1) and Chemistry (1).

\subsection{The VR and 360-degree experience}

In March 2020, ICOM Belgium Flanders and the Turnhout Museum decided to 3D-scan their storage facilities to create a VR tour (Figure 1) that was accessible on a computer with or without Oculus Quest [12]. However, during the workshop, it was not possible to use the Oculus Quest. Two case studies were used for the 360-degree representation: the Collection Center Netherlands (CCNL) and the special collection storage facilities of the National Library of the Netherlands (KB). For both cases, the images of the storage rooms were captured by the author using a 3D camera (Insta360 EVO). The static 360-degree images were organised on the technology platform ThingLink, and they were edited and equipped with interactive elements [e.g., KB had hyperlinks to copies of digitised books, a conservation report, additional images and other materials (Figure 2) [13]; CCNL linked to technical information about the building, storage and artworks, as well as hyperlinks to external resources, literature and detailed images], as shown in Figure 3. With these internal and external resources, the students could learn more about museum design, preventive conservation, and collection care.

The VR and 360-degree representations shown during the workshops included visualisation of the VR model (the scale, building geometry, room/space structure, etc.) as well as a walk-through within the site. The links to both the VR and 360-degree photography were made available for further use and consultation after the workshop. The students could access the links via laptop and smartphone.

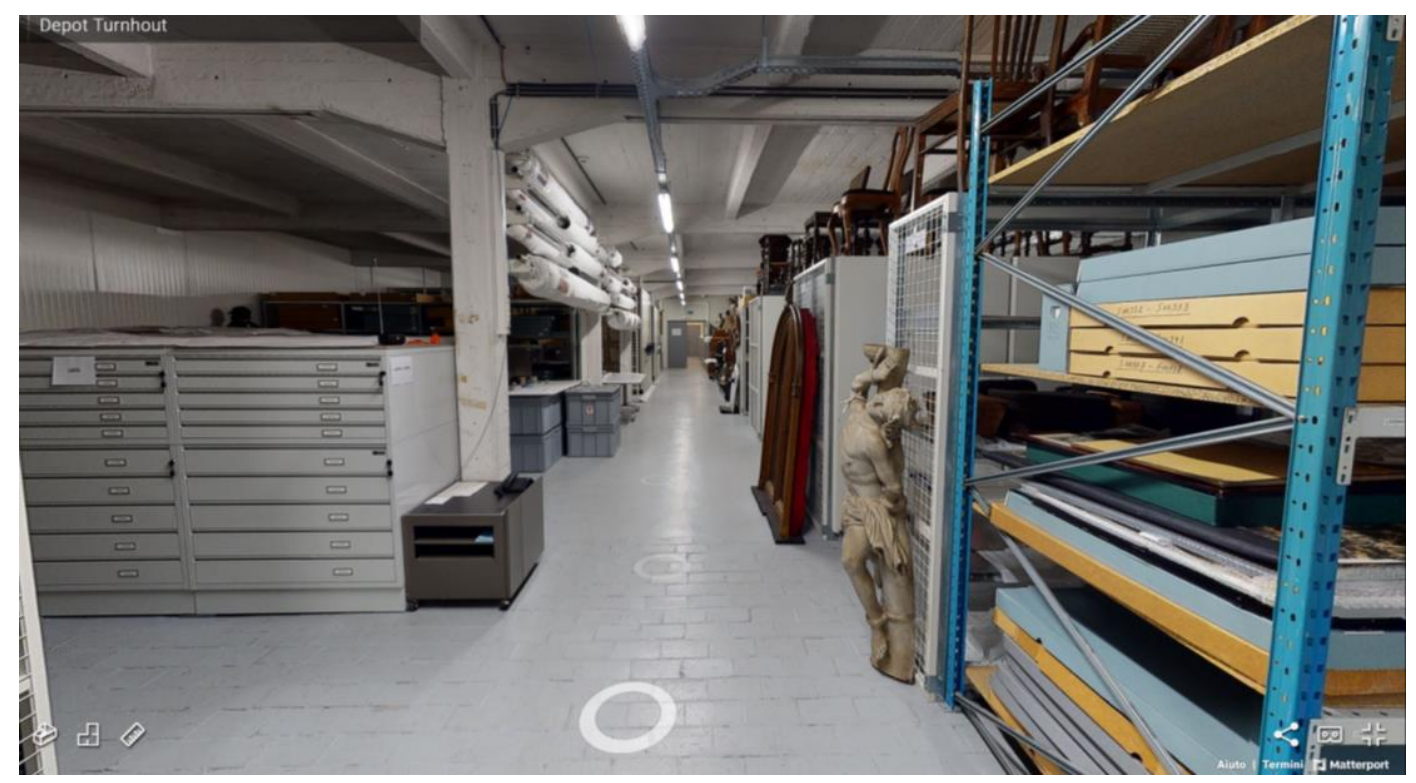

Figure 1. Frame of the virtual storage facility of the Turnhout Museum, Belgium (Depot Turnhout, 2020); presented by ICOM Belgium Flanders 
International Journal of Education (IJE) Vol.9, No.4, December 2021

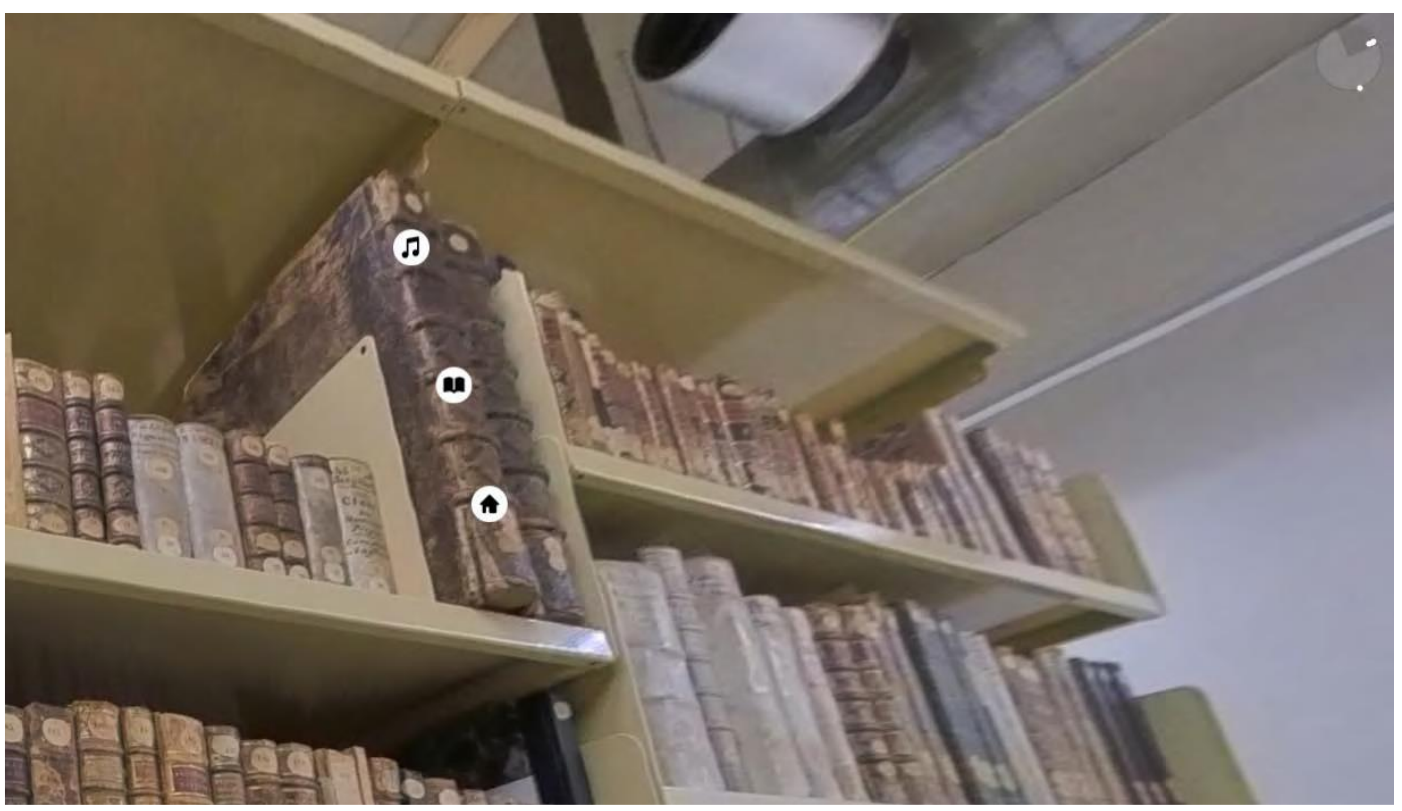

Figure 2. Frame of the 360-degree photography of the National Library of the Netherlands-KB (DIPOT, TU Delft)

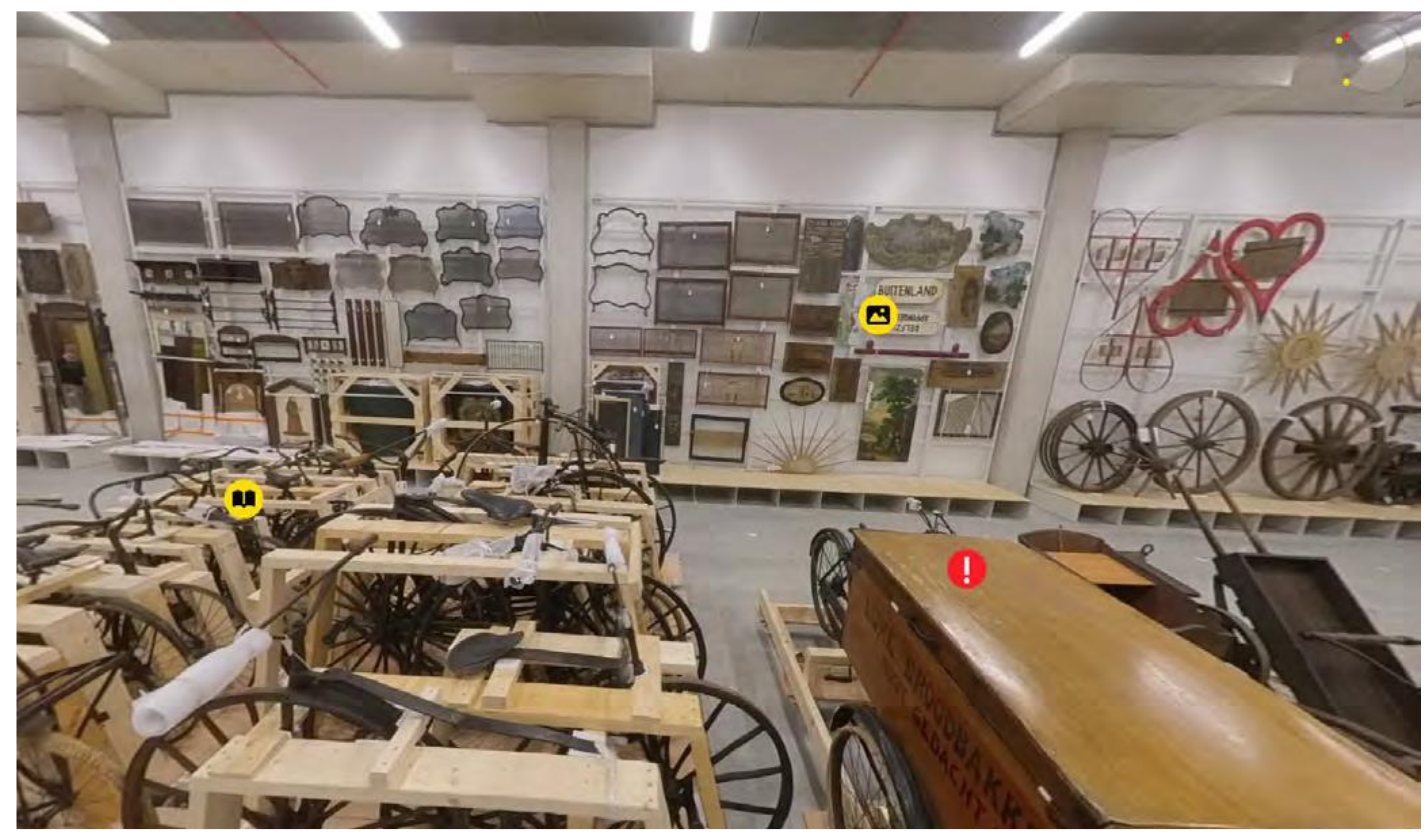

Figure 3. Frame of the 360-degree photography of the storage facility at the Collection Centre Netherlands, Amersfoort (DIPOT, TU Delft)

\subsection{Mixed-methods: qualitative, quantitative and experimental}

A combination of research methods that included qualitative and quantitative surveys was used (Figure 4). The first, of two surveys, was submitted to students two weeks before each workshop. The second survey was filled in on the last day of the workshop or in the following two weeks. Due to the students' workload and the short amount of time given to conducting the workshops, a mixture of qualitative and quantitative surveys (i.e., closed questions with ranking scales and open-ended questions) were designed to obtain data about the students' experiences with the 
museum environment (Table 2) and compare their answers with the second survey. Qualitative data was analysed and coding (labels) was added using ATLAS TI. The investigation took place over five months.

\subsubsection{Surveys and workshops}

The surveys included different sub-questions for each of the main research questions, and for each of the seven main questions, a label was created to identify each topic. To investigate student effectiveness, the first survey was administered before the student evaluations to assess their familiarity with museums, digital tools and virtual museums. A mix of quantitative (5 or 10point rating scale, Yes/No questions) and qualitative (to capture the participants' thoughts/experiences/opinions) questions were asked on the following subjects:

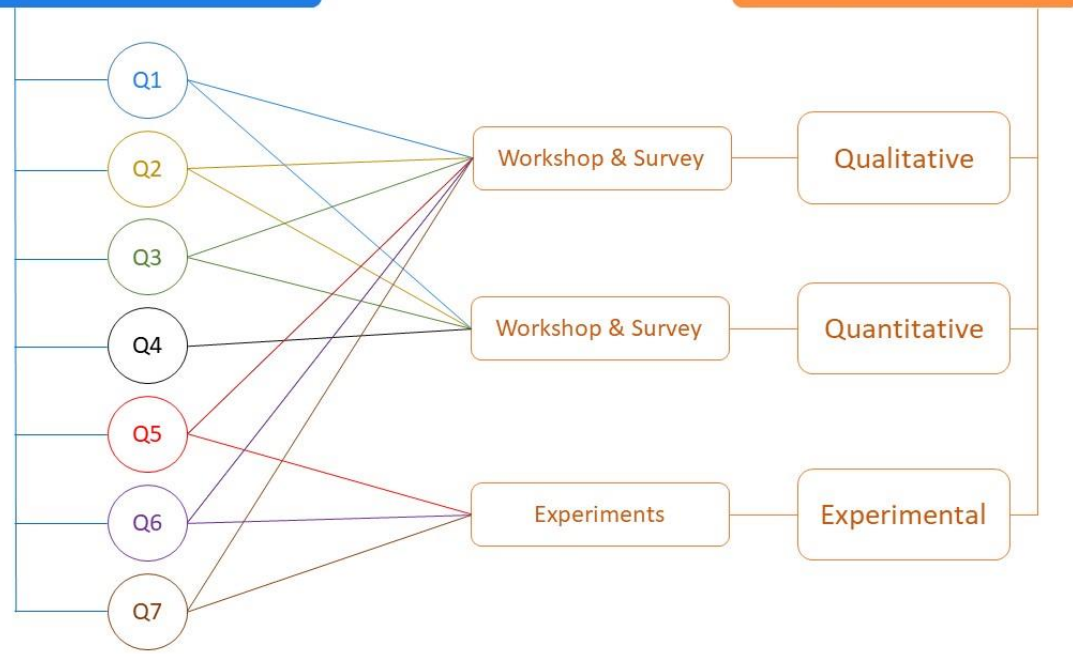

Figure 4. Overview of research questions and research methods.

Table 1. Students' experiences with the museum environment and the VR tools.

\begin{tabular}{|l|l|l|}
\hline $\begin{array}{l}\text { No } \\
\text { questions }\end{array}$ & Main research questions & Label \\
\hline Q1 & $\begin{array}{l}\text { What physical experience have students had with the museum } \\
\text { environment? }\end{array}$ & Perception \\
\hline Q2 & $\begin{array}{l}\text { What are the previous studies and interactions with museum design } \\
\text { aspects? }\end{array}$ & $\begin{array}{l}\text { Design } \\
\text { knowledge }\end{array}$ \\
\hline Q3 & What do students know about museum storage facilities? & Recognition \\
\hline Q4 & $\begin{array}{l}\text { How much are students familiar with virtual and digital museums, } \\
\text { exhibitions, archives and libraries? }\end{array}$ & Awareness \\
\hline Q5 & $\begin{array}{l}\text { How much do students think that 360-degree photography and VR } \\
\text { would help them understand and solve design problems? }\end{array}$ & Design success \\
\hline Q6 & $\begin{array}{l}\text { What difficulties have students encountered using 360-degree } \\
\text { photography and VR technology? }\end{array}$ & Visualisation \\
\hline Q7 & $\begin{array}{l}\text { How likely would they use 360-degree photography and VR tools in } \\
\text { their future design projects? }\end{array}$ & Interest \\
\hline
\end{tabular}


After submitting the first survey, a workshop was organised for each course. During each workshop, students received a lecture (by the author) that included information on preventive conservation, museum history and collections and museum practices (e.g., storage facilities, object handling and indoor climate). Students also had the opportunity to ask questions and raise issues relevant to their projects. The middle section of each workshop was dedicated to demonstrating and evaluating 360-degree photography of the library's storage and conservation centre and the VR storage model. This lasted approximately 30 minutes after which students had to complete the second survey (qualitative and quantitative). This was designed so that some of the questions from the first survey were repeated to see if students replied differently after the lecture. Other questions were designed to investigate the differences between 360-degree photography and VR tools, their effects on design and their response to navigation, visualisation and interest in using the tools.

\section{INTERPRETATION OF THE DATA}

Starting with the 'Perception' label, the first set of questions aimed to understand how students physically engaged with the museum's environment, its collections, professionals and users. Students had to answer questions about their familiarity with museums and how often they visited them before the COVID-19 pandemic. On a 5-point Likert scale, students replied that they visited museums once per year ( 9 students), once every three months (39 students), once a month (8 students) and two to three times per month (4 students). The majority of students preferred to visit art galleries $(80 \%)$, followed by history museums $(10 \%)$, natural history museums $(6 \%)$ and others. The answers related to their favourite museums often linked to a specific country and urban area (e.g., Van Gogh Museum, Rijksmuseum-Amsterdam; Escher Museum, Mauritshuis, Kröller-Müller and Prinsenhof in the Netherlands), iconic building (e.g., Neues Museum and Futurium, Berlin; Universum Bremen; the Acropolis, Athens; the Louvre, Paris; Museum of Modern Art, New York City; most of the students could also name the architects), where they grew up (e.g., Voorlinden, The Hague; Zuiderzeemuseum, Wierdijk; the Palace Museum, Beijing; Musée d'Histoire de Marseille, Marseille; Casa de Serralves, Porto; Museu Soares dos Reis, Porto; Bonnefantenmuseum, Maastricht; MARTa, Herford) and where they travelled on holidays (e.g., Schönbrunn Palace, Vienna; Museu d'Art Contemporani, Barcelona; Louisiana Museum of Modern Art, Humlebæk). They all had clear expectations about how professionals worked in and operated the museum, except for the role of the registrar, which only four students knew about. These results showed that the physical experience of museums play an important role in students' learning. Each student described how they were inspired by their visits and how different experiences (e.g., traveling and studio trips) influenced their projects and views.

'Design knowledge' aimed to understand students' previous studies and interactions with aspects of a museum's design. Seventy percent of the students worked or had an internship in an architecture studio for less than a year (master's students), between one and five years (masters and $\mathrm{PhD}$ students) and none (bachelor students). Six students worked directly for a museum (for a period of fewer than three months), and seventeen students worked on a museum's design within an architecture studio. Examples of where other students worked included working for project competitions, in a team restructuring and extending the Staatliche Kunsthalle Karlsruhe, in a design studio in China making an open-air free museum showing a non-existent archaeology site or assisting in the planning of an extension to the Taipei Fine Arts Museum in Taiwan. Answers to these questions were often related to their inspirations and memorable events in their path to becoming architects.

In both the first and second surveys, students were asked to list the important steps or elements they took into account before the design process (a). This was also to identify (b) the most important users of the museum; (c) which part of a museum was more relevant (from a visitor's 
and architect's point of view); (d) which part of the museum required the biggest space (Figure 5). The second survey was filled in after the lecture/workshop and provided students with information on preventive conservation and several museum examples and issues, which sometimes altered their answers in the second survey. The results from the second survey showed that museum location scores were higher than the scores in the first survey (Figure 5).

The answers to the question (a) were different in relation to the students' degrees. For bachelor's students, the words 'study' and 'inspiration' (taken from other projects) were mentioned 20 times, while the majority of master's students (28) added the research on the history of the area and various uses of buildings around the museum. Other master's students and the Ph.D. candidates (20), considered the visual intersection/context (e.g., if the building covered the current view or other important buildings/elements in the area); consulting the museum's employees, director, artists and other stakeholders were also relevant.

The most important users of a museum (question b) were the general visitors (56 students), employees (45 students), scholars (36 students), artists (19 students) and stakeholders (7 students).

The students' answers to the question (c) showed that, from a visitor's point of view, their route inside the museum was more relevant compared to other factors, such as a nice exterior and interior design, a functional design, restaurant/café services, a room for educational projects and the contents of the exhibition. For an architect, a functional design was more relevant.

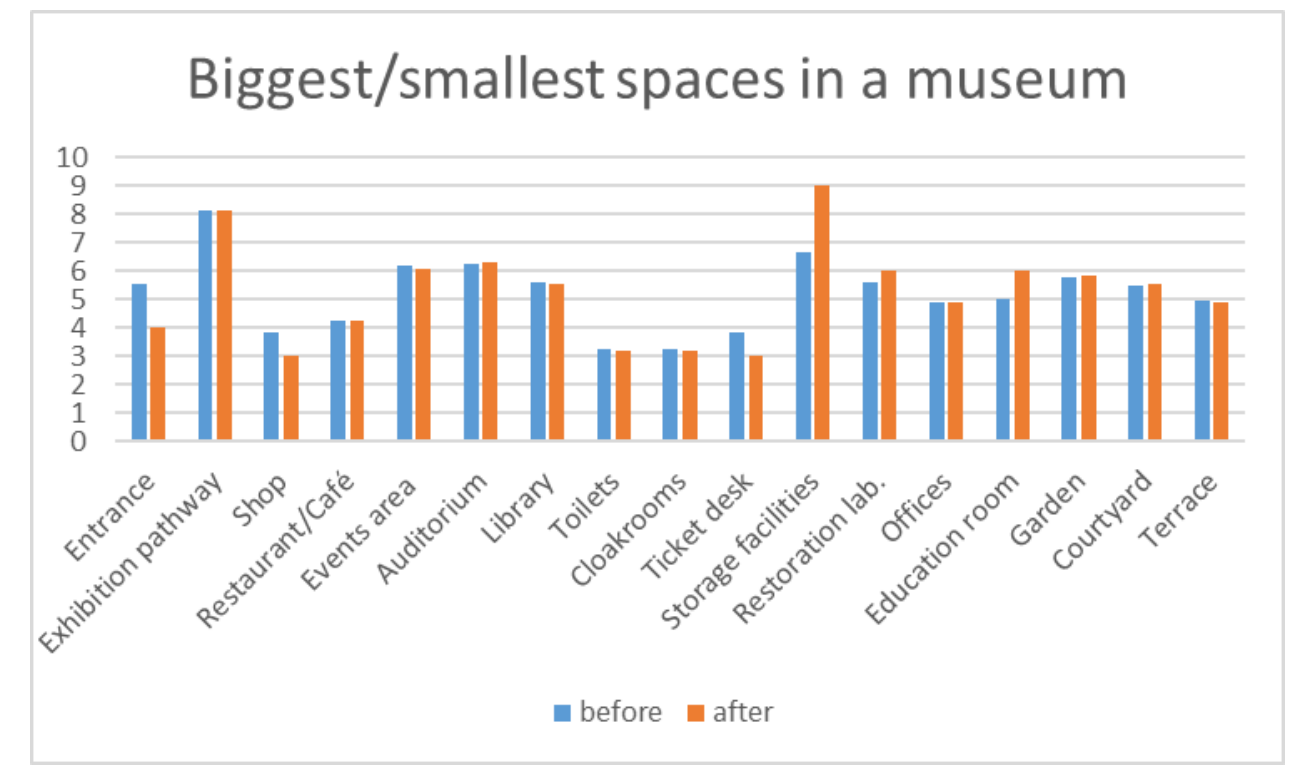

Figure 5. Average results of the biggest (10) and smallest (1) museum space rated by students on a 10 point Likert scale; answers from before and after the workshop

The 'Recognition' label aimed to understand students' knowledge about museum storage facilities. The results showed that only $17 \%$ of students (12) visited a museum's storage. In the first survey, $83 \%$ thought that storage was located in the basement, while in the second survey, answers changed (Figure 6). When asked about the amount of storage available in a museum, $51 \%$ did not know and 94\% thought that storage was only accessible to employees. Most of the students (70\%) thought that storage should be more accessible and made suggestions like using glass walls, having virtual tours, making it part of the museum route, separating the storage from the museum, conducting guided tours and organising special events. Moreover, some of them 
included a few known examples of accessible museum storage, such as the Schaulager in Münchenstein and Depot Boijmans van Beuningen in Rotterdam. Results showed that even though students knew very little about storage facilities, they were very interested in learning more and suggested solutions to solve accessibility, management and logistical issues. Even though museums are currently closed, most storage facilities are usually not accessible to the general public; therefore, the use of 360-degree photography and VR allowed access to this area and gave students the opportunity to learn more about how they are used (and not used). The students appreciated that they could access areas that are usually off-limits to the public.

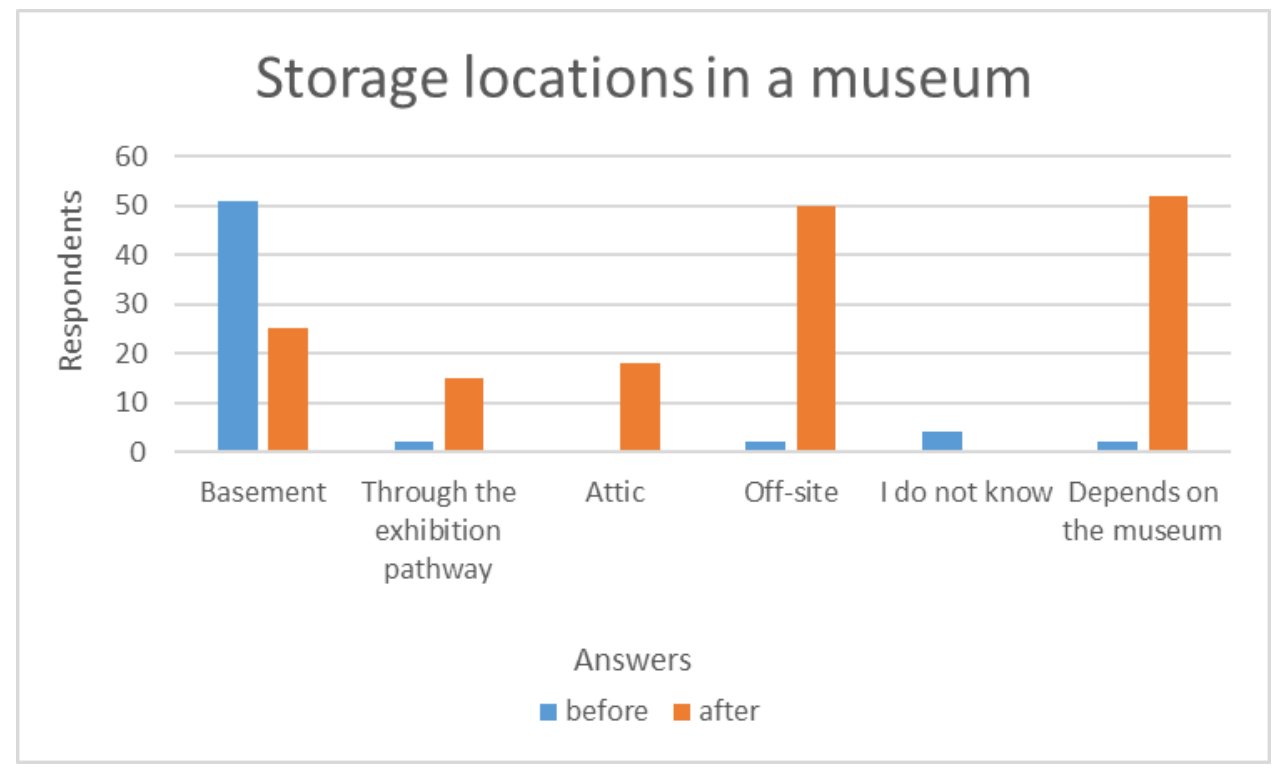

Figure 6. Student responses on the location of storage facilities in a museum, before and after the workshop

On 'Awareness', students revealed their familiarity with virtual museums, exhibitions, archives and libraries. Eighty per cent of students had never visited an online museum. The remaining $20 \%$ were characterised mostly by $\mathrm{PhD}$ students and a few master's students; the majority of these students found it was advantageous to zoom in to see the artworks better. However, $80 \%$ of these students thought it was somewhat fake compared to the real-life experience and $50 \%$ often felt alienated. Overall, $70 \%$ of students liked the idea of looking at the artworks without moving from home as they would not have to pay for a ticket. However, $80 \%$ missed the experience of being inside the building and physically interacting with its atmosphere. 'Museums are not just about the artworks, but an entire atmosphere that is created around them and the spatial qualities of the museum', said one $\mathrm{PhD}$ candidate. The 5-point Likert scale results showed that before COVID-19, students used physical libraries more than digital libraries for research and study purposes, and they had never or seldom used a physical and digital museum archive.

After navigating the VR and 360-degree photography platforms, students were asked to express their opinion about the usability and difficulties encountered in both tools to investigate if they could help understand and solve design problems. With the label 'Design success', a series of answers about the usability of the tools was provided. Overall, students found the 360-degree platform intuitive and easy to navigate. Starting from the section plan of the collection centre, they were able to visualise a 360-degree photography of each storage room. However, they thought that having to return to the main section to access other rooms was annoying; they wanted to 'walk through the room' as they did with VR, and one student compared it to Google Streetview. Students thought that the interactive icons pinned in the 360-degree platform were 
very useful in that they added information and explanations about the building and its objects; there were also extra pictures (close-ups) and hyperlinks to external data. Although students found this extra information useful for their projects, they considered it impractical to have to browse in another tab to access some of them. Students appreciated the fact they could access areas of the museum that were usually off-limits to the public. Furthermore, using the interactive icons' additional information as well as seeing some empty storage rooms, half-furnished or completely equipped rooms, helped them understand some of the issues of preventive conservation, design and planning. This part was missing in the VR representation as it was only possible to navigate the storage facility, although there was a measuring tool for scale on the VR model, which students found helpful. One weak point, according to the students, was that some pieces of the collection did not have any information attached to them.

The VR experience was considered 'very fluid with high image resolutions to look at details'; but some students felt like they were inside a dolls house and would rather be 'in the building for real'. Other comments included feelings of being 'lost in the room', the 'absence of information about the objects and the room', 'it was sometimes difficult to distinguish the objects', and if they were using a smartphone, 'the connection got lost and it was difficult to navigate'.

The label, 'Visualisation', allowed students to express their opinions about the strengths and weaknesses of both platforms. Some of them were anticipated in the previous 'Design success' label; however, in this section, students made suggestions on how to improve them.

The 360-degree platform was considered less interactive, more passive and static. 'It is fragmented: open, look around from a 360-degree point of view, close and next. I felt like a goldfish in its bowl: you can look around but you're not really going anywhere', was one of the comments. Another student added: 'The information bullets are great. I am curious though, when a lot of information is added, how you will integrate the icons? Because I would not like to have my whole screen filled with them. How will it be possible to select which items and building parts you want information about?'

The VR representation allowed students to explore the storage in a manner more similar to the real-life experience. 'It adds a reality check', said one student. Another continued, 'when one only sees photos of a place, one still identifies it as an isolated identity, and in the museums, everything has to be logically connected. Thus, to have this VR value-added is great to connect the analysis of the spaces individually and their connections to the overall perspective'. Furthermore, 'It is easier than in a real-life visit because I would probably not be able to get to this area of the museum or it may be in a very narrow corridor/corner. I had a better understanding of the space as a whole and I could use a VR headset'.

The last label, 'Interest', included responses on the future use of both the 360-degree platform and VR tools to improve future designs. All of the students related to both the platform and VR representation and considered their use in the future possible, but there were mixed opinions. They liked the idea of virtually navigating the museum space, especially parts that were not usually accessible, but, in general, the majority would not design with VR as they preferred to draw. Some of them responded, 'I do not think it adds a lot to a design because I believe an architecture design with a couple of well-made impressions shows more than a half-working 360view. I believe the power of the 360-view is more about taking us to existing places we cannot easily visit (e.g., museum storage)'. Some students thought they would use VR and 360-degree photography, but they would never realistically simulate the situation and experience one would have if physically there. Some students argued that in real life, one cannot see certain spaces or particulars that a high-resolution image could show, such as a spot high up in a building. Some thought it would be easier to identify problems in the design and could give an insight into spaces 
and experience of spaces before the building is built. Furthermore, the impact of multiple interventions or concepts could be explored. Some would gladly switch model-making with VR design to obtain a more realistic impression of spaces, and it would be more sustainable as there would be less waste material.

\section{Discussions AND CONClusions}

This work aimed to investigate whether the use of 360-degree photography and VR in a museum's environment could be beneficial in architectural education; results suggest that these technologies could advance architectural education and be beneficial for the museum design process. This does not automatically exclude other types of architecture, but museums and their storage facilities and buildings were the particular focus of this project. The participatory workshop and pedagogical approach were very appreciated by the students. They could engage the teacher and ask direct questions. Books and written sources were found to be important for students as accessory tools, but they preferred real examples applied to each of their queries. The use of surveys submitted before and after the workshop provided interesting results on the students' knowledge of museums and their storage facilities. An interesting result was the discovery that in one of the design courses, all of the necessary information to complete their project was not provided to students (e.g., the number of artworks in a permanent collection and storage, the number of employees) and before the lecture, they did not think such information would be very valuable in providing an adequate and functional museum design. Overall, it seems that different pedagogical tools, such as lectures, discussions, research and the use of VR helped students understand the pivotal role that storage areas play in museums and with it, the different activities that are carried out every day. Thus, how it is mandatory to adapt the design to have an optimal and functional museum machine. The results indicated how VR was a useful tool for visualising building form, design elements and understanding movement and circulation in specific areas, such as in museums. Architects usually consider a variety of scales and types of visualisation in the design process, but sometimes tend to forget about that variety and the impact of their designs. Having a simulation using these tools would work as a reminder about the impact of architectural design, not only from a heritage perspective but mainly from a practical/technical one. Using the 360-degree platform, students appreciated discovering each room and found it 'more comfortable' to always understand their location. They could find various information and be curious to find more. One student described the interactive icons as 'Easter eggs', and found gamification in this visualisation: a way to play and learn at the same time.

There were a few limitations in this study; for instance, only a small number of students (61) participated, but they were representative of international bachelor, masters and $\mathrm{PhD}$ students. Except for two courses, the potential to interact with students was limited to the day of the workshop. Students were also more responsive to fill in the surveys during the workshop than when asked by email afterwards. Due to the COVID-19 pandemic, the experiments and workshops had to be conducted online. This made it difficult to test the VR without headsets and controllers as students had to test it on the screen. Nevertheless, this pilot study provides a starting point for more focused research on the use of digital technologies in architecture and design education; it could also be tested on students from different fields, such as the arts, cultural heritage and museum studies with a focus on collections and objects. For museums, the platform could be improved and used to show the general public where the majority of the collection is usually placed and to create interesting educational projects.

The use of 360-degree photography proved to be a relatively easy tool to put together using a 3D camera and the Thinglink platform (others are also available online). To create VR, different skills and more time are required, which are not always at everyone's disposal. Several students 
suggested that a combination of the two tools would be valuable in future design courses. The virtual navigability provided by VR simulated the building space realistically, and the interactive tools provided in a 360-degree platform could be integrated into this. The integrated system could provide information about the building, and the VR spatial element could guide students in the learning phase of their design course. Even though the focus of this study was museums, these promising tools could be explored and adapted to different topics and used or tested in various courses. Another scope is to explore how the museum sector could enhance the work of designers and design educators, and ultimately raise the quality and creativity of design by providing structured access to design collections, showcasing design innovation, promoting conversation about design, building better public awareness and understanding of design culture and its contribution to creative economies.

\section{ACKNOWLEDGEMENTS}

This work would not have been possible without the help of many people. I am especially grateful to the students sho participated so willingly to this project. To all the employees and storage facility managers of the CCNL and KB who so generously shared their information and experiences. A special thanks to the VR-Lab of the TUD for providing the equipments.

\section{FUNDING}

Marzia Loddo's project has received funding from the European Union's Horizon 2020 research and innovation programme under the Marie Skłodowska-Curie grant agreement No 707404. The opinions expressed in this document reflect only the author's view. The European Commission is not responsible for any use that may be made of the information it contains.

\section{REFERENCES}

[1] Faisal, A. (2017). Computer science: Visionary of virtual reality. Nature, 551(7680), 298-299.

[2] Achten, H., W. Roelen, J.-Th. Boekholt, A. Turksma, and J. Jessurun, J. (1999). Virtual Reality in the Design Studio: The Eindhoven Perspective. In Architectural Computing from Turing to 2000, eCAADe Conference Proceedings, 169-177.

[3] Fernando, T., Wu, K. C. \& Bassanino, M. (2013). Designing a novel virtual collaborative environment to support collaboration in design review meetings. In Journal of Information Technology in Construction (ITcon), Vol. 18, pg. 372-396, http://www.itcon.org/2013/19.

[4] Coates, C. (2020). Virtual Reality is a big trend in museums, but what are the best examples of museums using VR. https://www.museumnext.com/article/how-museums-are-using-virtual-reality/. (Retrieved 4 March 2020).

[5] Angulo, A. (2015). Rediscovering Virtual Reality in the Education of Architectural Design: The immersive simulation of spatial experiences. In Ambiances - International Journal of Sensory Environment, Architecture and Urban Space 1: 1-23.

[6] Bartosh, A., \& Anzalone, P. (2019). Experimental Applications of Virtual Reality in Design Education. In K. Bieg, D. Briscoe, \& C. Odom (Eds.), Ubiquity and Autonomy - Paper Proceedings of the 39th Annual Conference of the Association for Computer Aided Design in Architecture, ACADIA 2019 (pp. 458-467).

[7] Milovanovic, J., Moreau, G., Siret, D., \& Miguet, F. (2017). Virtual and augmented reality in architectural design and education. In 17th International Conference, CAAD Futures 2017.

[8] Milgram, P. \& Kishino, F. (1994). A taxonomy of mixed reality visual displays. 77(12). IEICE Transactions on Information and Systems, 1321-1329.

[9] Kuipers, M. C., \& de Jonge, W. (2017). Designing from heritage: Strategies for conservation and conversion. Delft: TU Delft-Heritage \& Architecture.

[10] Loddo, M. (2020). Storage facilities for the collection of Western art museums. A focus on the Italian context. Santarcangelo di Romagna: Maggioli SPA. Politecnica series. p. 153. DOI https://doi.org/10.30448/UNI.43162.20. 
International Journal of Education (IJE) Vol.9, No.4, December 2021

[11] Pottgiesser U., Dragutinovic A., \& Loddo M. (Eds.), Momove - Modern Movement and Infrastructure. Contributions to the Docomomo virtual exhibition MOMOVE. In collaboration with the 18th Docomomo Germany Conference 2021 online from the Bauhaus Dessau, 26th February-31st March 2021. Detmold School at Bauhaus. (pp. 12-17).

[12] Depot Turnhout. (2020). Presented by ICOM Belgium Flanders. https://my.matterport.com/show/?m=Pm4cFdDpC6P. (Retrieved 13 September 2020).

[13] Loddo, M. Boersma, F., Kleppe, M. \& Vingerhoets, K. (2021). Experimenting with $360^{\circ}$ and VR representations as new access strategies to vulnerable physical collections: two case studies at the KB, National Library of the Netherlands. In IFLA Journal, Preservation and Conservation Section. 29 June, 2021 [https://doi.org/10.1177/03400352211023080]

\section{AUTHORS}

Marzia Loddo has worked as an expert in applied arts conservation in several Italian museums. She holds the European title of Doctor of Preservation of Architectural Heritage (2019, Politecnico di Milano).

In 2020, she published her first monograph, Storage Facilities for the Collections of Art Museums. A Focus on the Italian Context., on the topic of art collections storage.

She has worked as an expert in applied arts conservation and as a conservator in several Italian and overseas museums. Marzia is currently based in the Netherlands, where she is also an Affiliated Researcher with the Centre for Global Heritage and Development and, a member of ICOM and ICCROM. 
International Journal of Education (IJE) Vol.9, No.4, December 2021 